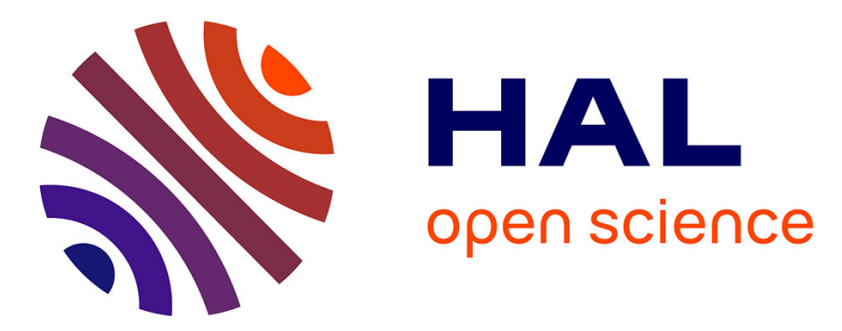

\title{
Expanding Ring Test : Numerical Simulation - Application to the Analysis of Experimental Data
}

\author{
F. Llorca, A. Juanicotena
}

\section{To cite this version:}

F. Llorca, A. Juanicotena. Expanding Ring Test: Numerical Simulation - Application to the Analysis of Experimental Data. Journal de Physique IV Proceedings, 1997, 07 (C3), pp.C3-235-C3-240. 10.1051/jp4:1997342 . jpa-00255499

\section{HAL Id: jpa-00255499 https://hal.science/jpa-00255499}

Submitted on 1 Jan 1997

HAL is a multi-disciplinary open access archive for the deposit and dissemination of scientific research documents, whether they are published or not. The documents may come from teaching and research institutions in France or abroad, or from public or private research centers.
L'archive ouverte pluridisciplinaire HAL, est destinée au dépôt et à la diffusion de documents scientifiques de niveau recherche, publiés ou non, émanant des établissements d'enseignement et de recherche français ou étrangers, des laboratoires publics ou privés. 


\title{
Expanding Ring Test: Numerical Simulation - Application to the Analysis of Experimental Data
}

\author{
F. Llorca and A. Juanicotena \\ Commissariat à l'Énergie Atomique, Centre de Valduc, 21120 Is-sur-Tille, France
}

\begin{abstract}
Résumé. La sollicitation dynamique appliquée à un matériau au cours d'une expérience d'expansion d'anneaux associe la propagation d'une onde de choc à une traction dynamique uniaxiale. Il est tout à fait interessant de réaliser la simulation numérique de l'expérience à l'aide d'un code aux éléments finis afin d'évaluer les différents éléments du montage expérimental (explosifs, ...), de comprendre le chargement mécanique réellement appliqué au matériau et enfin de développer la méthode d'interprétation des données expérimentales la plus adaptee.
\end{abstract}

\begin{abstract}
The dynamic loading applied to a material during an expanding ring experiment associates the propagation of a shock wave with a dynamic uniaxial tension. It seems judicious to perform a numerical simulation of the test with a finite element code in order to evaluate the various elements of the experimental assembly (explosive, ...), to understand the mechanical loading really applied to the material and to find the best numerical method used for the interpretation of the experimantal results.
\end{abstract}

\section{INTRODUCTION}

The primary objective of the expanding ring test is to evaluate the elastic-plastic behavior of materials submitted to high dynamic loadings during their life-time. The limits of the strain and strain-rate ranges which are expected to be obtained with this kind of test are respectively 0.6 and $5.10^{4} \mathrm{~s}^{-1}$. These experiments are particularly interesting because the dynamic behavior of materials is evaluated at strainrates higher than those possible with SHPB techniques.

A thin ring expands freely such that it is not submitted to a internal pressure. Under this motion, the kinematic energy is transformed into plastic flow : the strain-rate decreases. The material is then theoretically submitted to a dynamic uniaxial tensile stress [1-2]. The stress-strain-strain rate relations are given by :

$$
\sigma=-\rho R \ddot{R}, \varepsilon=\ln \left(\frac{R}{R_{0}}\right), \dot{\varepsilon}=\frac{\dot{R}}{R}
$$

where $\sigma, \varepsilon, \rho, \mathrm{R}_{0}, \mathrm{R}$ are the circumferential stress, the true strain, the mass density, the initial radius and the radius at time t. The mechanical behavior of materials can be determined at each time $t$ by an appropriate application of these equations (numerical integration and single numerical differentiation of $\dot{r}(t)$ to obtain $r(t)$ and $\ddot{r}(t)$ ). Inversely, the motion of the ring could be deduced if one knows the constitutive relation of the material and the initial velocity applied to the ring $V_{0}$.

The principle of the experiment is apparently very basic but the experimental results are often difficult to analyse. The initial kinematic energy is induced in the ring by the transmission and the propagation of a shock wave. The experimental arrangement is shown in figure 1. Upon detonation of the explosive, a compressive shock wave moves radially outward through the steel cylinder. After a short time, the ring separates from the steel core and expands radially by virtue of its own inertia. Radial velocity of the ring $\dot{r}(t)$ is directly monitored by mean of a Doppler Laser Interferometry technique while the radial displacement $r(t)$ is measured by mean of an ultra-fast opto-mechanical camera. Accuracy on displacement measurements is poor $(+/-10 \%)$ compared to the experimental data concerning radial velocity $(+/-1.5 \%)$. 


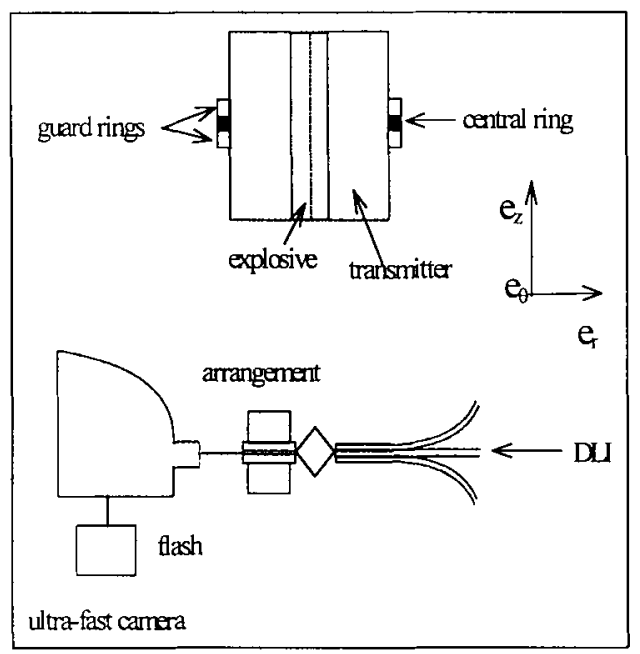

With the transmission of a high shock-wave to the ring (pressure level is up to $50 \mathrm{kbar}$ ), the microstructure of the material could be modified and its mechanical behavior influenced. Moreover, the loading is the result of the superposition of two distinct dynamic stress states : an hydrodynamic pressure (propagation of the shock wave and a uniaxial tension (free expanding). The shock conditions are short in time compared to the tensile conditions because the amplitude of the pressure decreases rapidely. It needs to understand the test from a mechanical point of view but in the litterature, this point has not bein yet examined. The analytical solution of the global problem is very complex, that's why a numerical simulation is proposed in this paper. As a reference for our numerical work, experimental results of an expanding ring test for copper OFHC are presented.

Figure 1. cross-sectional view of the expanding ring test.

Therefore, the numerical simulation of this experiment is developped (grid, type of calculation. constitutive relations, ...) ; first results (displacement and velocity curves) are compared to the experimental data. The good correlation makes us analyse the numerical data in terms of spheric and deviatoric components of the stress tensor. Finally, we make new recomandations concerning the transformation of the radial velocity data into stress-strain-strain rate curves, the aim of this final part being to propose a new method of interpreting the expanding ring test.

\section{AN EXPANDING RING TEST - OFHC COPPER}

Table 1 shows the parameters of the experiment.

Table 1. Characteristics of the test.

\begin{tabular}{|c|c|c|c|c|c|}
\hline material & $\begin{array}{c}\text { inside } \\
\text { diameter }\end{array}$ & $\begin{array}{c}\text { cross-section } \\
(\mathrm{mmxmm})\end{array}$ & transmitter & explosive & explosive \\
\hline copper & $47.5 \mathrm{~mm}$ & square $(3 \times 3)$ & steel XC38 & XXXX & $\begin{array}{c}\text { lenght }=60 \mathrm{~mm}, \\
\text { diameter }=6 \mathrm{~mm}\end{array}$ \\
\hline
\end{tabular}

\section{II.1. Film results}

We can observe five successive stages during the test :

1) the free expanding of the central ring and the rotative motions of the guard rings around axis $\overrightarrow{\mathrm{e}}_{\theta}$

2) glue throws between the central ring and the guard rings,

3) detonative products appear on both ends of the explosive,

4) fracturation of the transmitter,

5) detonative products appear in the fractures of the steel core.

\section{II.2. Rings recovery}

In figure 2 are shown different samples recovered after the test. We can observe that the shape of the guard rings is influenced by bidimensionnal effects because their cross-sections have been submitted to a $90^{\circ}$ rotation around axis $\overrightarrow{\mathrm{e}}_{\theta}$ : this observation is confirmed by the film. The central ring has fractured ( 7 fragments and 14 necked regions), the ultimate elongation is about $45.7 \%$. 


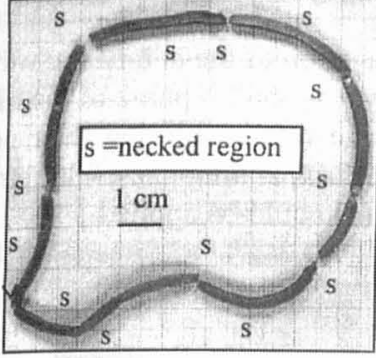

a)

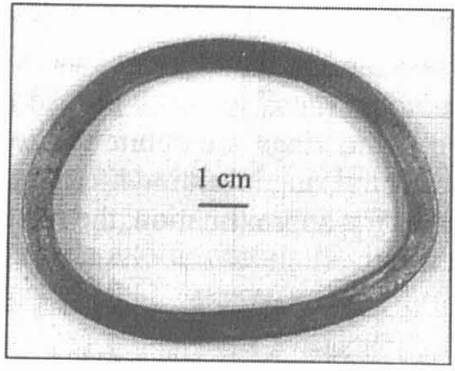

b)



c)

Figure 2. Samples recovered after the test : a) central ring - b) guard rings - c) striction area in the central ring

\section{II.3. Analysis of the DLI measurements}

Figure 3 presents the curve of radial velocity of the free surface of the ring.

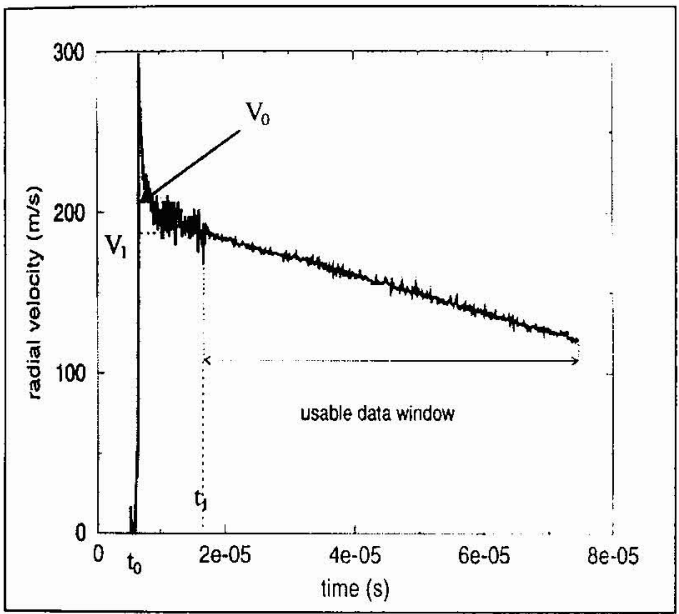

Figure 3. Curve of radial velocity of the ring.
Before time $t_{1}$, the ring is hydrodynamically balancing. The following part of the curve of material velocity corresponds to the pure uniaxial tensile loading. It is characterised by a monotoneous decreasing of velocity. Pressure level is about 3.7 Gpa at the transmitter-ring interface (see numerical results in the next paragraph); the initial velocity $V_{0}$ is approximated by :

$V_{0}=\frac{2 P}{\rho C_{0}}$ with $\mathrm{C}_{0}=$ shock velocity at $3.7 \mathrm{GPa}$.

We take the experimental mean value of $V=V_{0}$ during the earlier oscillation to be $200 \mathrm{~m} / \mathrm{s}$. When last equation is applied, the calculation gives $V_{0}=208$ $\mathrm{m} / \mathrm{s}$ which is in good agreement with the experimental evaluation.

\section{THE NUMERICAL SIMULATION OF THE TEST}

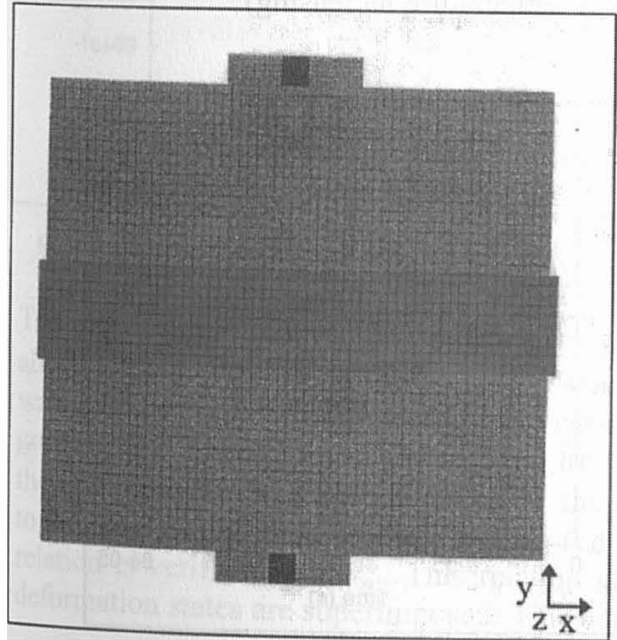

The simulation is performed on the HESIONE CEA hydrocode. The grid of the system is illustrated in figure 4 . It is an axisymetric representation because of the geometry and the dynamic loading. The drawing of the meshing is a "mirror option" : the real grid has been vertically projected. The system $\left(\vec{e}_{r}, \vec{e}_{\theta}, \vec{e}_{z}\right)$ is replaced by $(\vec{y}, \vec{z}, \vec{x})$ in the simulation. The calculation is performed with MieGruneisen equations of state and Steinberg-CochranGuinan (SCG) constitutive relations for the inert materials. The explosive is enterely represented by some specific developpments. Moreover, the calculation is lagrangian because most of the elements are not too deformed during their contribution to the expanding test. After $10 \mu \mathrm{s}$, the rings separate from the steel cylinder and only these clements are computed. 


\section{III.1. First results}

Figure 5 shows five stages of the test (initiation of the explosive - a -, propagation of the detonative waves $-a b-$, creation and transmission of the radial shock wave - $b c$ - and finally, expanding phase of the rings - $\mathrm{d}$ e -). Again, we confirme that the guard rings are submitted to a large rotation during their nonhomogeneous flight. The section of the central ring is not modified during the expanding phase : the stress field is uniform in a cross-section so, in a first approximation, the relations (1) could be applied.

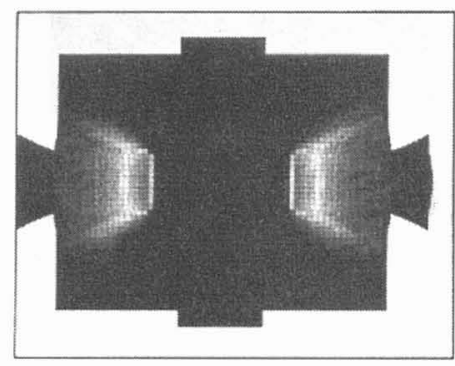

a)



d)

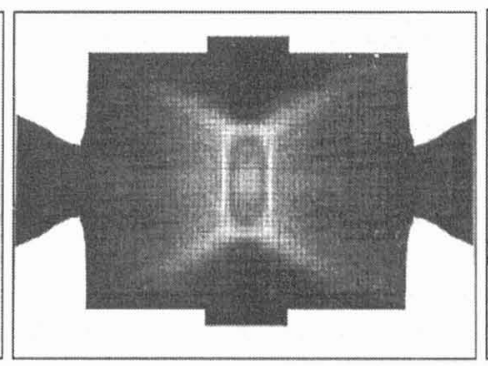

b)

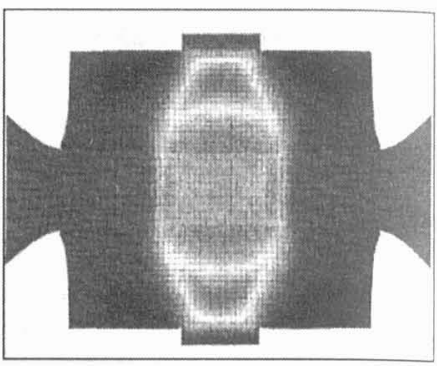

c)

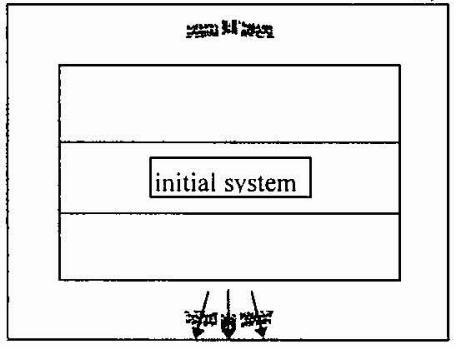

e)

Figure 5. Different stages during the experiment at $2 \mu \mathrm{s}(\mathrm{a}), 4 \mu \mathrm{s}$ (b), $6 \mu \mathrm{s}$ (c) and $8 \mu \mathrm{s}$ (d) and $20 \mu \mathrm{s}$ (e)

In figure 6, we compare the measured and the calculated profiles of radial velocity and radial displacement. It shows a good agreement concerning the chronology (beginning of the expanding phase). the amplitude of the mean initial velocity $V_{0}$ and the deformation at the start of the flight The peak of pressure at the interface between the steel transmitter and the ring is clearly well approximated which means that the initial mechanical conditions applied to the ring are correct. The difference between the respective slopes of the decreasing velocity curves is attributed to the constitutive relation of copper which does not take into account strain-rate influence. Moreover, the calculation is adiabatic because thermal softening is not included in the computational model for flow stress SCG $\left(\Delta T(30 \%)=\frac{0.9}{\rho C_{p}} \cdot \int_{\theta}^{0.3} \sigma d \varepsilon \approx 19^{\circ} \mathrm{C}\right.$ which is a very low amplitude of temperature increasing).
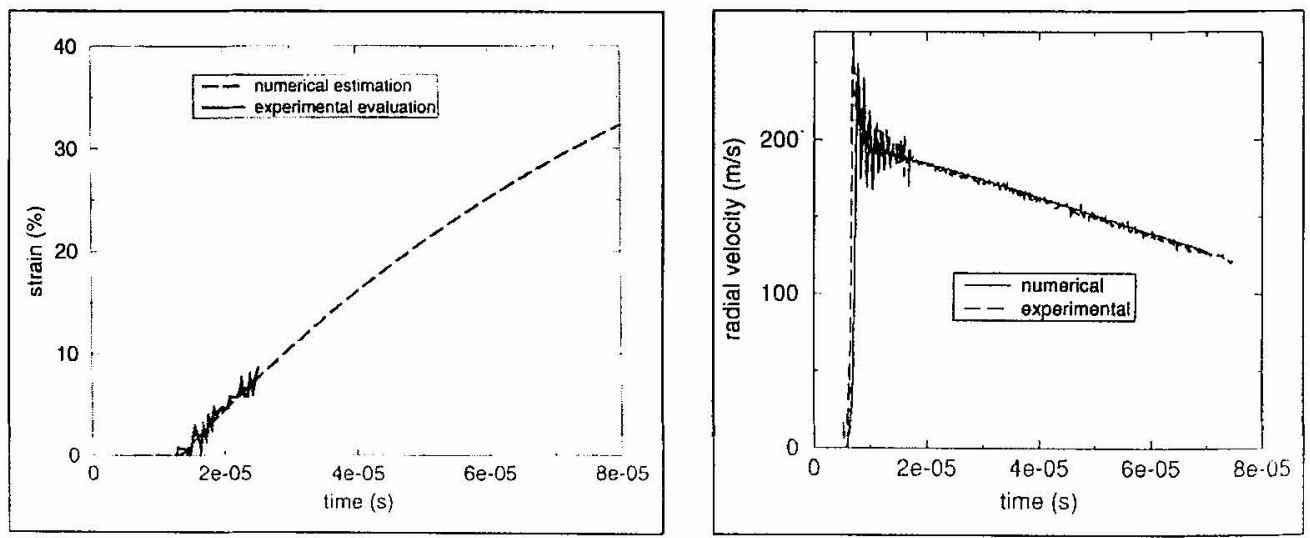

Figure 6. Comparison between experimental and calculated results. 
This good agreement shows that the test is globally well restituted by the proposed numerical simulation. This is important because it allows us to determine the geometrical properties or natures of all the elements of the system to be modified for optimizing future experiments.

\section{III.2. Mechanical analysis of the expanding ring test}

The stress tensor is separated into spheric and deviatoric components, respectively $P$ and $S_{x x}, S_{y y} S_{z z}$ We recall the relations for two particular cases :

a) a uniaxial tension in the $\mathrm{z}$ direction :

$$
\sigma=\left(\begin{array}{ccc}
0 & 0 & 0 \\
0 & 0 & 0 \\
0 & 0 & \sigma_{z}
\end{array}\right)=\left[\begin{array}{ccc}
\frac{\sigma_{z}}{3} & 0 & 0 \\
0 & \frac{\sigma_{z}}{3} & 0 \\
0 & 0 & \frac{\sigma_{z}}{3}
\end{array}\right]+\left[\begin{array}{ccc}
-\frac{\sigma_{z}}{3} & 0 & 0 \\
0 & -\frac{\sigma_{z}}{3} & 0 \\
0 & 0 & \frac{2 \sigma_{z}}{3}
\end{array}\right]=-P . I+S .\left[\begin{array}{ccc}
-1 & 0 & 0 \\
0 & -1 & 0 \\
0 & 0 & 2
\end{array}\right] \text { with } S=\frac{\sigma_{z}}{3}>0
$$

b) a uniaxial deformation in the y direction :

$\sigma=\left[\begin{array}{ccc}\sigma_{x} & 0 & 0 \\ 0 & \sigma_{y} & 0 \\ 0 & 0 & \sigma_{x}\end{array}\right]=\left[\begin{array}{ccc}\frac{2 \sigma_{x}+\sigma_{y}}{3} & 0 & 0 \\ 0 & \frac{2 \sigma_{x}+\sigma_{y}}{3} & 0 \\ 0 & 0 & \frac{2 \sigma_{x}+\sigma_{y}}{3}\end{array}\right]+\left[\begin{array}{ccc}\frac{\sigma_{x}-\sigma_{y}}{3} & 0 & 0 \\ 0 & -2\left(\frac{\sigma_{x}-\sigma_{y}}{3}\right) & 0 \\ 0 & 0 & \frac{\sigma_{x}-\sigma_{y}}{3}\end{array}\right]=-P . I+S\left[\begin{array}{ccc}1 & 0 & 0 \\ 0 & -2 & 0 \\ 0 & 0 & 1\end{array}\right]$ with $S=\frac{\sigma_{x}-\sigma_{y}}{3}$.

Figures 7 and 8 represent the calculated components of the stress tensor as functions of time.

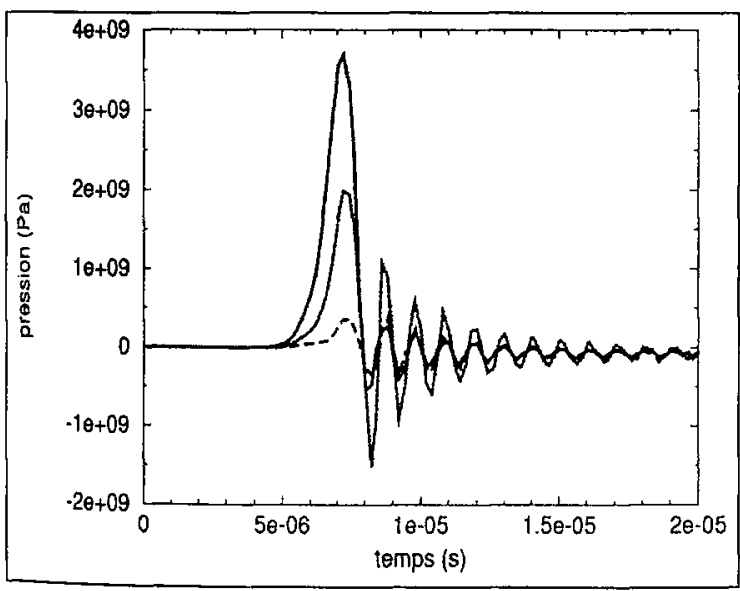

Figure 7. Spheric component of the stress tensor.

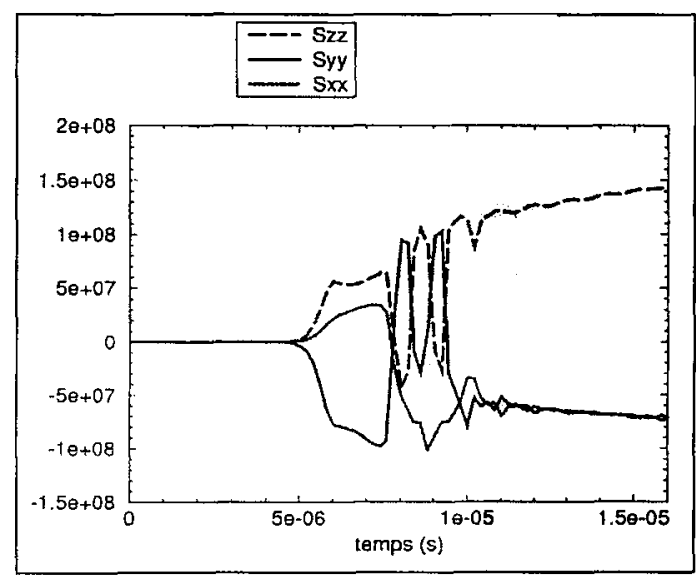

Figure 8. Deviatoric components of the stress tensor.

The time history of pressure shows that the spheric loading is a regular buid-up of pressure (its duration is about $2.5 \mu \mathrm{s}$ ) which indicates that its influence would be less important than that of a classical shock wave : it is a kind of quasi-isentropic compression which means lower strain-rate loading and temperature growing. After the travel of the induced first shock, the curve shows a regular balancing of pressure into the ring (between $8 \mu \mathrm{s}$ et $15 \mu \mathrm{s})$. During the application of the shock $(5 \mu \mathrm{s}-7.5 \mu \mathrm{s})$, the stress field is close to the uniaxial deformation state in the $\mathrm{y}\left(\mathrm{e}_{\mathrm{r}}\right)$ direction. For a shock propagating in this direction, the next relation is verified : $S_{x r}=S$... This relation is not verified because the uniaxial tension and the uniaxial deformation states are superimposed. This combination is fixed in time : the profile of pressure is damped 
and after $10 \mu \mathrm{s}$, the material is only submitted to a pure uniaxial tensile stress (the relation $S_{x x}=S_{y y}=-\frac{S_{z z}}{2}$ is then verified).

\section{III.3. Conclusions concerning the interpretation of experimental data}

These results indicate that the uniaxial tensile stress is always effective even at the beginning of the flight stage. So, if we consider the problem of the transformation of experimental velocity measurements. one can conclude that the first part of the curve may be considered (in litterature -see [1], it is not taken into account). As seen in figure 3, the balancing zone of the velocity curve is delimited by two couples of parameters $\left(V_{0}, t_{0}\right)$ and $\left.V_{l}, t_{l}\right)$. Between these limits, we assume the profile of velocity to be quasi-linear $\left(v(t)=a t+b\right.$ with $a=\frac{V_{0}-V_{1}}{t_{0}-t_{1}}$ and $\left.b=\frac{V_{I} t_{0}-V_{0} t_{1}}{t_{0}-t_{1}}\right)$ then the new radius at any time $t>t_{I}$ is given by :

$$
\begin{aligned}
& r(t)=r\left(t_{I}\right)+\int_{l_{I}}^{t} \dot{r}(t) d t=r\left(t_{0}\right)+a t^{2}+V_{0} t+\int_{t_{I}}^{t} \dot{r}(t) d t \\
& \neq r\left(t_{0}\right) \quad \text { numerical integration }
\end{aligned}
$$

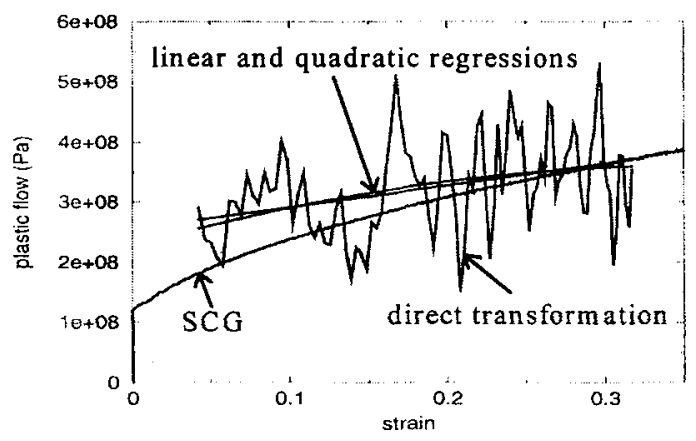

The acceleration is evaluated after a fitting process by a finite difference method ; the stress, the strain. and the strain rate are given by the classical equations. Figure 9 represents a comparison between the plastic stress for the SCG constitutive law and the transformed velocity signals for the experiment. We must recall that the experimental curve is adiabatic and the influence of temperature is not taken into account in the simulation. Comparison between the two curves show that mean value of flow stress is well approximated by the constitutive law. But we cannot conclude concerning the effect of strain-rate because more experiments are needed.

Figure 9. Evolution of the plastic flow during the expanding ring test.

\section{CONCLUSION}

We have developped a numerical approach of the expanding ring test which allows us to better understand the mechanical loading applied to the material elements and to optimize the interpretation of experimental data. Next step concerns the introduction of these experimental data into an constitutive relations updating procedure [3].

\section{ACKNOWLEDGMENTS}

The authors gratefully acknowledge the contributions of Alain PEREZ and Patrice ANTOINE for the experiment preparation, Thomas BERTRAND for his contribution on numerical simulation.

\section{REFERENCES}

1. R.H. WARNES, T.A. DUFFEY, R.R. KARPP, A.E. KARDEN in Shock Waves and High Strain Rate Phenomena in Metlas : Concepts and Applications, M.A. Meyers and L.E. Murr, eds Plenum (1981) 2326.

2. S. DUJARDIN. G. GA7EAUD. A. LICHTENBERGER in Journal de Physique, Colloque ( $\because$ Supplément 10 $^{\circ}$, tome 49. Septembre 1988. 55-62.

3. A. IIAANICOTLNA. F. I.LORCA. this conference. 